\title{
Avaliação de pontas de Jato Plano na Deposição da Calda de Pulverização com Diferentes Combinações de Plantas de FEIJÃo, Brachiaria plantaginea e Bidens pilosa
}

\author{
Evaluation of Flat Fan Nozzles in Spray Deposition on Different Combinations of Bean Plants, \\ Brachiaria plantaginea and Bidens pilosa
}

\author{
RODRIGUES-COSTA, A.C.P. ${ }^{2}$, COSTA, N.V. ${ }^{2}$, CARDOSO, L.A. ${ }^{3}$, PEREIRA, M.R.R. ${ }^{3}$ e \\ MARTINS, D. ${ }^{4}$
}

\begin{abstract}
RESUMO - Objetivou-se com este trabalho avaliar a ponta XR na deposição da calda de pulverização com diferentes combinações de plantas de feijão, Brachiaria plantaginea e Bidens pilosa, em dois volumes de aplicação, com e sem a adição de surfatante Silwet. Foi utilizado como traçador o corante Azul Brilhante FDC - 1 na concentração de 500 ppm para quantificar a deposição. Os tratamentos constituíram-se de sete combinações de plantas: (feijão), (B. plantaginea), (B. pilosa), (feijão $+B$. plantaginea), (feijão $+B$. pilosa), $(B \cdot$ plantaginea $+B \cdot$ pilosa $)$ e (feijão $+B$. plantaginea $+B$. pilosa). O delineamento experimental foi o inteiramente casualizado. Foram avaliadas as pontas de jato plano XR 110015 VS e XR 11002 VS com volumes de aplicação de 150 e $200 \mathrm{~L} \mathrm{ha}^{-1}$, respectivamente, com e sem a presença do Silwet a $0,05 \% \mathrm{v} \mathrm{v}^{-1}$. Após a aplicação, as plantas foram imediatamente coletadas e, em seguida, lavadas em $100 \mathrm{~mL}$ de água destilada, para posterior quantificação do traçador em espectrofotômetro. As pontas XR apresentaram comportamento distinto na deposição das gotas de pulverização nas espécies estudadas; a adição de um surfatante à calda de pulverização aumentou a uniformidade da deposição nos alvos e contribuiu para a redução do volume de aplicação.
\end{abstract}

Palavras-chave: picão-preto, capim-marmelada, volume de aplicação.

\begin{abstract}
The objective of this study was to evaluate flat fan nozzle spray deposition on different combinations of the common bean plants, Brachiaria plantaginea and Bidens pilosa, in two volumes of application, with and without the addition of surfactant. Brilliant blue FDC-1 was used as tracer solution at the concentration of $500 \mathrm{ppm}$ to evaluate the deposition. The treatments consisted of 7 combinations of plants: (common bean); (B. plantaginea); (B. pilosa); (common bean + B. plantaginea); (common bean + B. pilosa); (B. plantaginea + B. pilosa) and (common bean + B. plantaginea $+\boldsymbol{B}$. pilosa). The experiment was arranged in a randomized block design. The flat fan nozzles XR 110015 VS and XR 11002 VS were evaluated, with volumes of application of 150 and $200 \mathrm{~L} \mathrm{ha}^{-1}$, respectively, with and without the surfactant Silwet at $0.05 \% v v^{-1}$. After application, the plants were immediately collected and washed in $100 \mathrm{~mL}$ of distilled water for posterior tracer quantification in the spectrophotometer. The flat fan nozzles presented distinct behavior in droplet deposition on the species studied; the addition of a surfactant to the spray solution increased deposition uniformity, and contributed to the reduction of the volume application.
\end{abstract}

Keywords: beggarticks, Alexandergrass, application volume.

Recebido para publicação em 21.5.2009 e na forma revisada em 17.12.2010.

2 Professor Adjunto, Universidade Estadual do Oeste do Paraná - UNIOESTE/CCA, Marechal Cândido Rondon-PR, <andreiacpr@hotmail.com>; ${ }^{3}$ Aluno de Pós-Graduação, Dep. de Produção Vegetal, Faculdade de Ciências Agronômicas, Universidade Estadual Paulista "Júlio Mesquita Filho" - FCA/UNESP, Fazenda Lageado, Caixa Postal 237, 18603-970 Botucatu-SP; ${ }^{4}$ Professor Adjunto, Dep. de Produção Vegetal, FCA/UNESP, Botucatu-SP. 


\section{INTRODUÇÃO}

Muitos são os fatores que influenciam negativamente a qualidade da pulverização, dentre os quais se destacam: calibração inadequada do equipamento, falta de controle do tamanho e distribuição das gotas pulverizadas, volume de aplicação inadequado, má cobertura sobre o alvo, altura inadequada da barra de pulverização, época de aplicação e escolha incorreta das pontas de pulverização (Sharp, 1973).

Da mesma forma, a utilização de doses e volumes reduzidos exige aumento da eficiência da deposição de calda sobre o alvo; caso contrário, a dose depositada poderá ser insuficiente para causar o efeito biológico desejável (Downer et al., 1997). É função da tecnologia de aplicação proporcionar a distribuição uniforme da calda pulverizada.

A qualidade da pulverização é um fator que pode interferir na eficiência de controle de herbicidas pós-emergentes, principalmente os que apresentam baixa translocação na planta, a exemplo do acifluorfen-sódio e bentazon, bem como dos herbicidas de manejo, como diquat, flumioxazin e paraquat, que são registrados para a cultura do feijoeiro (Rodrigues \& Almeida, 2005). Dessa maneira, o estudo de deposição de gotas de pulverização nessa cultura pode minimizar os efeitos negativos no ambiente devido à ocorrência de deriva, escorrimento de produto da folha para o solo, além dos efeitos decorrentes das características morfológicas e anatômicas de cada espécie, que podem dificultar a retenção e/ou apresentar-se como barreira à penetração de herbicida nos órgãos vegetais, como rugosidade e espessura da cutícula, presença de ceras epicuticulares, densidade de estômatos e tricomas (Hess \& Falk, 1990; Procópio et al., 2003; Ferreira et al., 2007; Guimarães et al., 2009).

De acordo com Monquero et al. (2005), a retenção das gotas herbicidas, por exemplo, é melhor em plantas que apresentam folhas com superficie cuticular plana, sem a presença de grande quantidade de cristais de cera, os quais podem evitar que as gotas entrem diretamente em contato com a membrana cuticular.

A eficácia do controle químico está relacionada a diversos fatores, dentre os quais as características da planta destacam-se como variável importante, sendo atualmente pouco estudada. Segundo Hess \& Falk (1990), a topografia da superficie foliar e a presença de ceras e tricomas podem influenciar a distribuição de um determinado herbicida aplicado sobre a folha, e a utilização de adjuvantes pode reduzir a influência negativa apresentada por essas estruturas foliares. Assim, a molhabilidade da superficie foliar pode ser considerada fator importante no processo de penetração dos herbicidas na planta, sendo fundamental no aumento da eficiência no controle de plantas daninhas.

O mecanismo de ação dos surfatantes está relacionado com o aumento efetivo da área de contato da gota pulverizada com a superfície foliar, a dissolução ou rompimento de ceras epicuticulares, a prevenção ou retardamento da formação de cristais na gota pulverizada e a promoção da absorção dos compostos pela via estomática (Stock \& Holloway, 1993).

O surfatante Silwet pode proporcionar reduções na tensão superficial da calda de pulverização em aproximadamente 19,5 a $22,9 \mathrm{mN} \mathrm{m}^{-1}$, assegurando excelente molhamento da superficie adaxial da folha e permitindo a penetração da calda pela via estomática (Buick et al., 1993). Mendonça et al. (1999) avaliaram os surfatantes Extravon, Aterbane e Silwet em folhas de Cyperus rotundus e verificaram que o Silwet apresentou-se mais eficiente entre os surfatantes testados, tanto em termos de redução da tensão superficial quanto no aumento da área de molhamento da gota de pulverização.

Com relação ao manejo químico em pósemergência de plantas daninhas, é importante destacar que estas ocorrem aleatoriamente e em diferentes densidades no meio das linhas de plantio; esse comportamento pode influenciar na quantidade de gotas interceptadas pelas espécies presentes na área, ressaltando-se, ainda, que as diferenças morfológicas das espécies podem intensificar o efeito guarda-chuva no momento da aplicação, o que proporciona falhas de controle ou mesmo fitotoxicidade nas culturas.

Segundo Souza et al. (2007), a avaliação de depósitos em cada planta daninha, e não em cada população, está associada também às 
suas pequenas dimensões; portanto, as plântulas são expostas por um tempo extremamente curto (da ordem de $0,1 \mathrm{~s}$ ) ao jato de aplicação, o que, somado a fatores como oscilações e altura da barra, vento, tamanho da gota e estádio de desenvolvimento, implica grande variabilidade dos depósitos unitários obtidos. Esses autores destacam ainda que a morte ou sobrevivência de cada planta depende da dose depositada sobre ela e não sobre toda a população. A avaliação da deposição média dá algumas informações importantes sobre a eficiência das tecnologias de aplicação em estudo, mas falha por não permitir a associação entre dose (aumento ou redução) e porcentagem de eficiência.

Dessa forma, existem poucas informações na literatura referentes ao desempenho de pontas de pulverização na deposição de calda de pulverização em diferentes condições de infestação de plantas daninhas em área de produção de feijão; além de dados sobre a quantidade e uniformidade de distribuição do ingrediente ativo sobre a superficie-alvo e os efeitos desses fatores sobre a eficiência de herbicidas de ação sistêmica e de contato. Ressalta-se que a utilização de técnicas de pulverização de modo inadequado pode exigir aumento na dose de herbicidas para que elevados niveis de controle sejam alcançados em condições de campo e, consequentemente, reduzir a seletividade do herbicida em relação à cultura, bem como proporcionar maior perda de produto por deriva.

O presente trabalho teve como objetivo avaliar duas pontas de jato plano na deposição da calda de pulverização em diferentes combinações de plantas de feijão, Brachiaria plantaginea e Bidens pilosa, em dois volumes de aplicação, com e sem a adição do surfatante Silwet.

\section{MATERIAL E MÉTODOS}

O estudo foi realizado em casa de vegetação da Faculdade de Ciências Agronômicas - FCA/UNESP, campus de Botucatu-SP, no ano de 2006. O delineamento experimental utilizado foi o inteiramente casualizado, com quatro repetições. Foram avaliadas plantas de feijão do cultivar Carioca e plantas daninhas das espécies $B$. pilosa e B. plantaginea.
As plantas de feijão, B. plantaginea e $B$. pilosa foram semeadas em vasos com capacidade de $5 \mathrm{~L}$ nas seguintes combinações: vasos semeados somente com (feijão), (B. plantaginea), (B. pilosa), (feijão $+B$. plantaginea), (feijão $+B$. pilosa), $(B$. plantaginea $+B$. pilosa) e (feijão + $B$. plantaginea $+B$. pilosa). As densidades das plantas para a formação das combinações foram: três plantas de feijão, cinco plantas de B. plantaginea e duas plantas de B. pilosa.

Na avaliação da deposição da calda utilizaram-se as pontas de jato plano Teejet XR 110015 VS e XR 11002 VS para obter os volumes de aplicação de 150 e $200 \mathrm{~L} \mathrm{ha}^{-1}$, respectivamente, com e sem a presença do surfatante Silwet (copolímero de poliéster e silicone) a $0,05 \% \mathrm{v} \mathrm{v}^{-1}$.

A aplicação da calda de pulverização com o traçador (Azul Brilhante - 500 ppm) foi realizada com o auxílio de um pulverizador estacionário, com pressão de $175 \mathrm{kPa}$, equipado com uma barra de pulverização posicionada a $0,5 \mathrm{~m}$ de altura das plantas, munida de quatro pontas de pulverização com espaçamento de $0,5 \mathrm{~m}$ entre bicos. As pontas de pulverização XR utilizadas na pressão de $175 \mathrm{kPa}$ proporcionam gotas finas (diâmetro mediano volumétrico $\mathrm{DMV}=100$ a $175 \mu \mathrm{m})$, de acordo com o fabricante (Spraying Systems Co., 2007).

Na ocasião da aplicação da calda de pulverização, as plantas de feijão encontravam-se no estádio V4 com três trifólios (Quintela, 2001); já as plantas daninhas apresentavam-se com 2-3 pares de folhas para $B$. pilosa e 3-4 perfilhos para $B$. plantaginea. No momento da aplicação a umidade relativa do ar encontrava-se em $93 \%$ e a temperatura era de $19{ }^{\circ} \mathrm{C}$.

Foram coletadas imediatamente após a aplicação da calda 12 plantas de feijão, 20 plantas de $B$. plantaginea e oito plantas de $B$. pilosa por tratamento. As plantas foram acondicionadas em sacos plásticos e em seguida levadas ao laboratório, para serem lavadas em $100 \mathrm{~mL}$ de água destilada. Para quantificar a solução do corante Azul Brilhante após lavagem das plantas, determinou-se a densidade óptica (absorbância = $630 \mathrm{~nm}$ ) das soluções, utilizando-se um espectrofotômetro de UV visível GBC, modelo Cintra 20. 
Após a lavagem, as plantas foram colocadas em sacos de papel etiquetados e levadas a uma estufa de ventilação forçada de ar, para secagem. Após 72 horas, a uma temperatura de $60 \pm 5^{\circ} \mathrm{C}$, as plantas foram retiradas e pesadas, determinando-se a massa seca.

Determinou-se a quantidade do traçador depositada nas plantas, utilizando-se espectrofotômetro; os dados obtidos de absorbância (630 $\mathrm{nm}=$ comprimento de onda utilizado na determinação da concentração do traçador) foram transformados em dados de volume ( $\mu \mathrm{L}$ de calda $\mathrm{g}^{-1}$ de massa seca), por meio da expressão matemática $\mathrm{C}_{1} \cdot \mathrm{V}_{1}=\mathrm{C}_{2} \cdot \mathrm{V}_{2}$, em que: $\mathrm{C}_{1}$ = concentração inicial na calda de aplicação $\left(\mathrm{mg} \mathrm{L}^{-1}\right) ; \mathrm{V}_{1}=$ volume retido pelo alvo $(\mathrm{mL}) ; \mathrm{C}_{2}=$ concentração detectada em densidade óptica ( $\left.\mathrm{mg} \mathrm{L}^{-1}\right) ; \mathrm{e} \mathrm{V}_{2}=$ volume de diluição da amostra de cada planta $(\mathrm{mL})$.

Os dados obtidos dos depósitos (em porcentagem) foram ajustados pelo modelo de Gompertz $\left(\mathrm{F}=\mathrm{e}^{\wedge}\left(\mathrm{a}-\mathrm{e}^{\wedge}\left(-\mathrm{b}-\mathrm{c}^{*} \mathrm{X}\right)\right)\right)$, para representar a frequência acumulada $(\mathrm{F})$ da deposição da calda pulverizada, em porcentagem. Adotou-se o valor de 4,60517 para o parâmetro "a" do modelo, o qual representa a assintota máxima da curva, em que "e $\mathrm{e}^{\mathrm{a}}=100$, conforme o modelo ajustado por Velini (1995). O deslocamento da curva ao longo do eixo x é representado pelo módulo do parâmetro "a", e

Tabela 1 - Análises de regressão das frequências acumuladas dos depósitos da calda de pulverização com e sem a presença de Silwet em plantas de feijão, utilizando o modelo de Gompertz, bem como as médias, modas e medianas $\left(\mu \mathrm{L} \mathrm{g}^{-1}\right)$, dos diferentes volumes de aplicação

\begin{tabular}{|c|c|c|c|c|}
\hline \multirow{2}{*}{$\begin{array}{c}\text { Parâmetro } \\
\text { da } \\
\text { equação }\end{array}$} & \multicolumn{3}{|c|}{ Frequência acumulada $(\%)=\mathrm{e}^{\wedge}\left[\mathrm{a}-\mathrm{e}^{\wedge}\left(-\mathrm{b}-\mathrm{c}^{*} \mathrm{x}\right)\right]$} \\
\cline { 2 - 5 } & \multicolumn{2}{|c|}{ XR $110015 \mathrm{VS}$} & \multicolumn{2}{|c|}{$\mathrm{XR} 11002 \mathrm{VS}$} \\
\cline { 2 - 5 } & $\begin{array}{c}\text { sem } \\
\text { surfatante }\end{array}$ & $\begin{array}{c}\text { com } \\
\text { surfatante }\end{array}$ & $\begin{array}{c}\text { sem } \\
\text { sem } \\
\text { surfatante }\end{array}$ & $\begin{array}{c}\text { com } \\
\text { surfatante }\end{array}$ \\
\hline $\mathrm{a}$ & 4,605 & 4,605 & 4,605 & 4,605 \\
\hline b & $-3,580$ & $-3,650$ & $-4,150$ & $-2,119$ \\
\hline c & 0,021 & 0,025 & 0,017 & 0,008 \\
\hline Média & 197,122 & 165,612 & 283,866 & 278,228 \\
\hline Mediana & 191,578 & 160,661 & 268,840 & 324,056 \\
\hline Moda & 173,786 & 146,000 & 247,024 & 276,271 \\
\hline F & $105,391^{-1}$ & $46,961 *$ & $149,027^{*}$ & $62,507 *$ \\
\hline CV (\%) & 3,398 & 5,815 & 1,958 & 3,047 \\
\hline
\end{tabular}

$\mathrm{x}=$ porcentagem de depósito do traçador em relação ao total aplicado; a, b e c são estimativas dos parâmetros do modelo para o traçador. * significativo a $5 \%$ de probabilidade a inclinação ou concavidade da curva em relação à frequência acumulada, pelo parâmetro "c". Além disso, para melhor visualização, optou-se por apresentar as frequências não acumuladas $\left(\mathrm{FN}=\mathrm{c}^{*} \mathrm{e}^{\wedge}\left(\mathrm{a}-\mathrm{b}-\mathrm{c}^{*} \mathrm{X}-\mathrm{e}^{\wedge}\left(-\mathrm{b}-\mathrm{c}^{*} \mathrm{X}\right)\right)\right)$, que correspondem à derivada primeira do modelo. As frequências acumuladas e não acumuladas do modelo de Gompertz permitem a interpretação biológica dos resultados. Para facilitar a visualização das informações, a derivada primeira corresponde à moda da deposição da solução pulverizada nos alvos específicos (Velini, 1995).

Os valores de média, moda e mediana também foram estabelecidos no trabalho. A precisão do ajuste dos dados do modelo de Gompertz foi avaliada por meio dos coeficientes de determinação $\left(R^{2}\right)$ e pela soma dos quadrados dos resíduos das equações.

\section{RESULTADOS E DISCUSSÃO}

Nas Tabelas $1,2,3,4,5$ e 7 são apresentados os resultados das análises de regressão das frequências acumuladas dos depósitos da calda de pulverização com e sem a presença de surfatante em combinações de plantas de feijão, $B$. plantaginea e $B$. pilosa, utilizando-se o modelo de Gompertz, bem como as médias, modas e medianas $\left(\mu \mathrm{L} \mathrm{g}^{-1}\right)$, dos diferentes volumes de aplicação.

Tabela 2 - Resultados das análises de regressão das frequências acumuladas dos depósitos da calda de pulverização com e sem a presença de Silwet em plantas de Brachiaria plantaginea, utilizando o modelo de Gompertz, bem como as médias, modas e medianas $\left(\mu \mathrm{L} \mathrm{g}^{-1}\right)$, dos diferentes volumes de aplicação

\begin{tabular}{|c|c|c|c|c|}
\hline \multirow{4}{*}{$\begin{array}{c}\text { Parâmetro } \\
\text { da } \\
\text { equação }\end{array}$} & \multicolumn{4}{|c|}{ Frequência acumulada $(\%)=\mathrm{e}^{\wedge}\left[\mathrm{a}-\mathrm{e}^{\wedge}\left(-\mathrm{b}-\mathrm{c}^{*} \mathrm{x}\right)\right]$} \\
\hline & \multirow{2}{*}{\multicolumn{2}{|c|}{$\frac{\text { XR } 110015 \text { VS }}{150\left(\mathrm{~L} \mathrm{ha}^{-1}\right)}$}} & \multirow{2}{*}{\multicolumn{2}{|c|}{$\frac{\text { XR } 11002 \mathrm{VS}}{200\left(\mathrm{~L} \mathrm{ha}^{-1}\right)}$}} \\
\hline & & & & \\
\hline & $\begin{array}{c}\text { sem } \\
\text { surfatante }\end{array}$ & $\begin{array}{c}\text { com } \\
\text { surfatante }\end{array}$ & $\begin{array}{c}\text { sem } \\
\text { surfatante }\end{array}$ & $\begin{array}{c}\text { com } \\
\text { surfatante }\end{array}$ \\
\hline $\mathrm{a}$ & 4,605 & 4,605 & 4,605 & 4,605 \\
\hline b & $-0,789$ & $-1,725$ & $-1,883$ & $-2,019$ \\
\hline c & 0,005 & 0,008 & 0,007 & 0,009 \\
\hline Média & 97,977 & 200,134 & 267,316 & 209,297 \\
\hline Mediana & 220,098 & 268,143 & 341,871 & 255,408 \\
\hline Moda & 150,286 & 221,154 & 286,170 & 216,167 \\
\hline $\mathrm{F}$ & $133,517 *$ & $799,343 *$ & $268,041 *$ & $168,890^{*}$ \\
\hline CV $(\%)$ & 6,463 & 1,326 & 1,699 & 2,949 \\
\hline
\end{tabular}

$\mathrm{x}=$ porcentagem de depósito do traçador em relação ao total aplicado; a, b e c são estimativas dos parâmetros do modelo para o traçador. ${ }^{*}$ significativo a $5 \%$ de probabilidade. 
A frequência não acumulada é obtida pela derivada primeira do modelo de Gompertz. A concavidade da curva da frequência não acumulada evidencia a uniformidade da deposição. Quanto mais plana a curva, maior é a frequência de valores extremos, caracterizando maior amplitude de depósito na população amostrada, e o pico da curva apresenta os valores de depósito que mais se repetiram na população de plantas amostradas (Velini, 1995).

Na Figura 1 podem-se observar as frequências acumuladas (FA\%): (A) e não acumuladas (FNA\%): (B), em função da deposição da calda de pulverização com e sem Silwet nos volumes de aplicação utilizados nas plantas de feijão. Observou-se que a presença do Silwet proporcionou maior deposição no volume de $200 \mathrm{~L} \mathrm{ha}^{-1}$ e ocorreu maior uniformidade de distribuição das gotas no volume de $150 \mathrm{~L} \mathrm{ha}^{-1}$, porém com o menor valor de moda de $146 \mu \mathrm{L}$ de calda para cada grama de massa seca (Tabela 1).

Ambas as pontas XR avaliadas e utilizadas na pressão de $175 \mathrm{kPa}$ proporcionaram gotas finas $(\mathrm{DMV}=100$ a $175 \mu \mathrm{m})$ (Spraying Systems Co., 2007), o que pode aumentar o risco de deriva, dependendo das condições ambientais. Contudo, Cunha et al. (2003) afirmam que, em geral, valores de DMV inferiores a $250 \mu \mathrm{m}$ indicam risco potencial de deriva, que acontece principalmente em virtude das gotas menores que $100 \mu \mathrm{m}$. Em contrapartida, valores de DMV superiores a $500 \mu \mathrm{m}$ sugerem problemas de escorrimento, que, comumente, ocorrem com gotas maiores que $800 \mu \mathrm{m}$. Esses autores ressaltam ainda que a adição de surfatantes à calda de pulverização pode alterar o espectro de gotas pulverizadas e que, no caso da adição de óleo vegetal à calda de pulverização, pode ocorrer aumento do diâmetro das gotas e diminuir o risco potencial de deriva.

Fernandes et al. (2007) verificaram DMV de 260 e $240 \mu \mathrm{m}$ das gotas produzidas por pontas XR 110015 VS sob pressões de 200 e $300 \mathrm{kPa}$, respectivamente, com a adição de $0,1 \%$ do espalhante adesivo não iônico alquilfenol (Haiten) na calda de aplicação.

Entretanto, apesar de falta de informações na literatura sobre o efeito do Silwet na alteração do espectro de gotas produzidas pelas pontas XR avaliadas, pode-se inferir que a redução da tensão superficial das gotas causada pelo Silwet no volume de $200 \mathrm{~L} \mathrm{ha}^{-1}$ pode ter proporcionado maior aglomeração das gotas após a deposição nas folhas do feijoeiro, o que provavelmente ocasionou o escorrimento das gotas para outras partes da planta, acumulando-se em depósitos irregulares. Com a utilização do menor volume, o efeito da aglomeração de gotas após a deposição nas folhas pode ter sido reduzido pela menor quantidade de gotas produzidas pela ponta XR 110015 VS.

Segundo Maciel et al. (2001), as aplicações com as pontas XR 11002 VS (jato leque) e TXVK4 (jato cônico) sem a adição de surfatante na calda de pulverização proporcionaram aumento em torno de 106,4 e 66,9\%, respectivamente, da deposição em plantas de feijão, quando comparada com as aplicações utilizando-se as mesmas pontas de pulverização com a adição do surfatante Aterbane $\left(0,5 \% \mathrm{v} \mathrm{v} \mathrm{v}^{-1}\right)$. Esses autores ressaltam que pode ter ocorrido
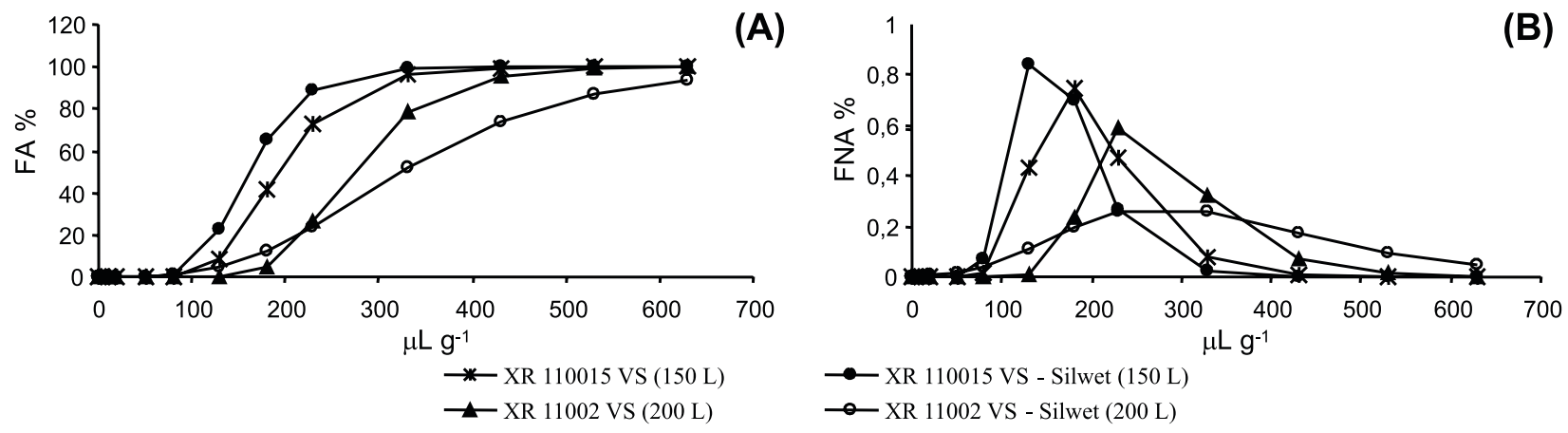

Figura 1 - Frequências acumuladas (FA\%): (A) e não acumuladas (FNA\%): (B), em função da deposição da calda de pulverização com e sem Silwet e dos volumes de aplicação, em $\mu \mathrm{L} \mathrm{g}^{-1}$ de massa seca das plantas de feijão. 
escorrimento ou não aderência das gotas de pulverização nas folhas, devido à redução da tensão superficial da água proporcionada pelo surfatante Aterbane.

Cunha et al. (2005) verificaram 21,5 e $61,1 \%$ mais deposição de gotas nas porções superior e inferior, respectivamente, de plantas de feijão aos 30 DAE com a utilização do volume de aplicação de $250 \mathrm{~L} \mathrm{ha}^{-1}$ do que com o volume de $125 \mathrm{~L} \mathrm{ha}^{-1}$. Esses autores observaram ainda que as gotas formadas nas aplicações com as pontas de jato cônico vazio (ATR) ficaram mais sujeitas à deriva que as produzidas com as pontas de jato plano (API), especialmente quando se empregou baixo volume de aplicação. Da mesma maneira, Raetano \& Bauer (2004) constataram que, de modo geral, as aplicações com maior volume (100 L ha-1) apresentaram médias significativamente maiores de depósitos na planta, ao se comparar com as de menor volume (60 L ha $\mathrm{L}^{-1}$ ), sobre os niveis de depósitos em plantas de feijoeiro aos $26 \mathrm{DAE}$.

Para as plantas de B. plantaginea (Tabela 2 e Figura 2), a presença de Silwet proporcionou acréscimo na quantidade de deposição somente no volume de $150 \mathrm{~L} \mathrm{ha}^{-1}$ em $47,1 \%$ em relação ao tratamento sem surfatante e decréscimo de $24,5 \%$ no volume de $200 \mathrm{~L} \mathrm{ha}^{-1}$, porém com maior uniformidade de distribuição de gotas, em detrimento do proporcionado pelo volume de $150 \mathrm{~L} \mathrm{ha}^{-1}$. Provavelmente, a ação do Silwet no maior volume pode ter promovido perdas de calda devido ao efeito de escorrimento das gotas, e esse escorrimento pode ter auxiliado no espalhamento da calda pela planta. Já no menor volume o efeito de escorrimento das gotas pode ter sido minimizado. Dessa forma, pode-se inferir que as plantas de $B$. plantaginea no estádio de 3-4 perfilhos podem ter a capacidade de retenção de gotas reduzida com a utilização de volume de aplicação superior a $150 \mathrm{~L} \mathrm{ha}^{-1}$ com a adição de surfatante.

Tomazela et al. (2006) avaliaram a deposição de gotas com a ponta XR em $B$. plantaginea no estádio de duas a três folhas e observaram que, à medida que se decresceu o volume de calda de pulverização por hectare, ocorreram acréscimos na porcentagem de depósito nas plantas e, concomitantemente, decréscimos na porcentagem depositada no solo, indicando maior eficácia quanto ao objetivo de atingir o alvo biológico.

Costa et al. (2005) avaliaram a área de molhamento de gotas de pulverização nas folhas das gramineas Brachiaria mutica, Brachiaria subquadripara e Panicum repens e verificaram efeito positivo da adição do Silwet na solução de glyphosate, uma vez que houve dificuldade no momento da deposição da gota, principalmente na face adaxial da folha dessas espécies, provocada pelo efeito de repelência da gota de pulverização das soluções de água destilada e glyphosate sem adjuvante.

Hess \& Falk (1990) explicam que maiores depósitos de ceras epicuticulares na superfície adaxial da folha podem reduzir o espalhamento da gota de pulverização nessa superfície. Mendonça (2000) observou nas gramíneas Brachiaria decumbens, Brachiaria plantaginea
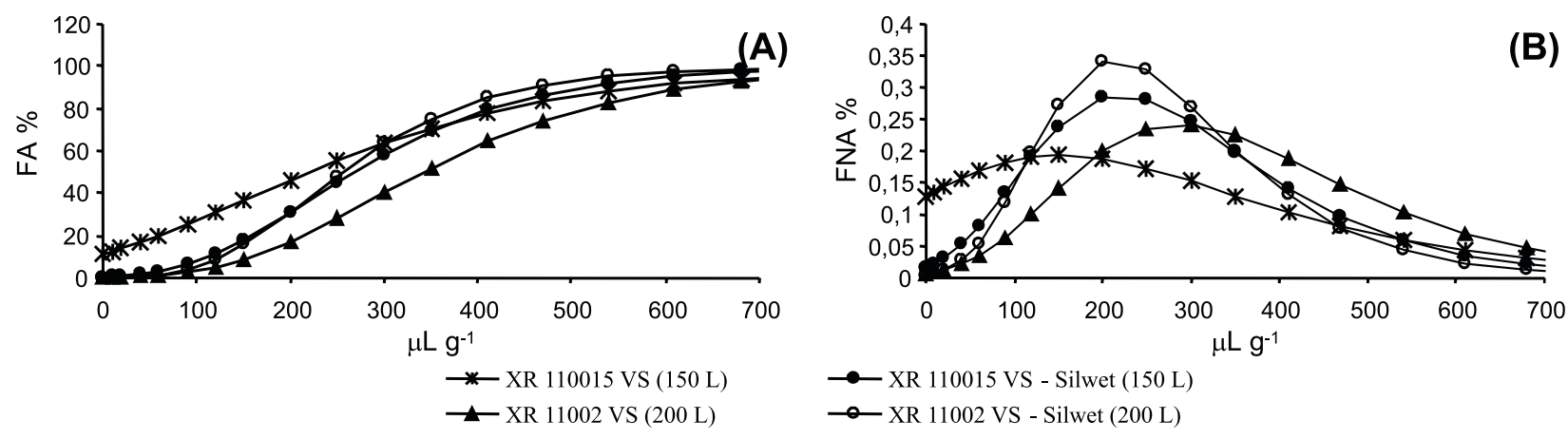

Figura 2 - Frequências acumuladas (FA\%): (A) e não acumuladas (FNA\%): (B), em função da deposição da calda de pulverização com e sem Silwet e dos volumes de aplicação, em $\mu \mathrm{L} \mathrm{g}^{-1}$ de massa seca das plantas de Brachiaria plantaginea. 
e Panicum maximum maiores áreas de molhamento nas faces abaxiais da folha, proporcionadas pelos adjuvantes Aterbane e Silwet em água destilada, o que é explicado pelos menores depósitos de ceras epicuticulares, evidenciados pelos estudos ultraestruturais da superfície foliar realizados com a técnica de microscopia eletrônica de varredura.

Verificou-se que os maiores depósitos sobre as plantas de $B$. pilosa foram obtidos nos tratamentos sem a adição do surfatante Silwet; quando se utilizou o surfatante a deposição das gotas foram 18,9 e $25,6 \%$ inferiores para os volumes de 150 e $200 \mathrm{~L} \mathrm{ha}^{-1}$, respectivamente (Tabela 3). Esse fato ocorreu provavelmente em função do escorrimento causado pelo grande volume depositado e pela baixa tensão superficial da calda decorrente da atuação desse adjuvante, bem como devido às características da topografia da superficie foliar e à presença de ceras e tricomas nas folhas dessa espécie de planta daninha (Procópio et al., 2003; Costa et al., 2005; Monquero et al., 2005; Ferreira et al., 2007).

A redução na deposição observada nos tratamentos com o surfatante Silwet pode indicar que a quantidade de gotas com herbicida de ação de contato retida nas folhas de $B$. pilosa poderia não ser suficiente para provocar a morte das plantas, além do aumento do risco de contaminação ambiental devido ao escorrimento para o solo. Dessa forma, uma alternativa para minimizar esse efeito seria a utilização de volume menor e mais concentrado do ingrediente ativo, além de pontas de pulverização que proporcionem gotas finas.
Na Figura 3 estão apresentadas as frequências acumuladas (FA\%): (A) e não acumuladas (FNA\%): (B) dos depósitos nas plantas de B. pilosa. Observa-se que $150 \mathrm{~L} \mathrm{ha}^{-1}$ foi o volume que proporcionou a melhor uniformidade de distribuição de gotas de pulverização e que a adição do Silwet piorou essa distribuição.

Na combinação de plantas de feijão e B. plantaginea (Tabela 4 e Figura 4), a presença do Silwet na calda de pulverização conferiu acréscimos nos depósitos para as plantas de feijão de 65,3 e 39,1\% para os volumes de 150 e $200 \mathrm{~L} \mathrm{ha}^{-1}$, respectivamente, e decréscimos

Tabela 3 - Resultados das análises de regressão das frequências acumuladas dos depósitos da calda de pulverização com e sem a presença de Silwet em plantas de Bidens pilosa, utilizando o modelo de Gompertz, bem como as médias, modas e medianas $\left(\mu \mathrm{L} \mathrm{g}^{-1}\right)$, dos diferentes volumes de aplicação

\begin{tabular}{|c|c|c|c|c|}
\hline \multirow{4}{*}{$\begin{array}{c}\text { Parâmetro } \\
\text { da } \\
\text { equação }\end{array}$} & \multicolumn{4}{|c|}{ Frequência acumulada $(\%)=\mathrm{e}^{\wedge}\left[\mathrm{a}-\mathrm{e}^{\wedge}\left(-\mathrm{b}-\mathrm{c}^{*} \mathrm{x}\right)\right]$} \\
\hline & \multirow{2}{*}{\multicolumn{2}{|c|}{$\frac{\text { XR } 110015 \mathrm{VS}}{150\left(\mathrm{~L} \mathrm{ha}^{-1}\right)}$}} & \multirow{2}{*}{\multicolumn{2}{|c|}{$\begin{array}{c}\text { XR } 11002 \text { VS } \\
200\left(\mathrm{~L} \mathrm{ha}^{-1}\right) \\
\end{array}$}} \\
\hline & & & & \\
\hline & $\begin{array}{c}\text { sem } \\
\text { surfatante }\end{array}$ & $\begin{array}{c}\text { com } \\
\text { surfatante }\end{array}$ & $\begin{array}{c}\text { sem } \\
\text { surfatante }\end{array}$ & $\begin{array}{c}\text { com } \\
\text { surfatante }\end{array}$ \\
\hline $\mathrm{a}$ & 4,605 & 4,605 & 4,605 & 4,605 \\
\hline $\mathrm{b}$ & $-3,824$ & $-2,560$ & $-4,990$ & $-3,857$ \\
\hline $\mathrm{c}$ & 0,013 & 0,010 & 0,008 & 0,008 \\
\hline Média & 326,775 & 363,783 & 715,835 & 476,989 \\
\hline Mediana & 332,580 & 281,395 & 662,115 & 502,201 \\
\hline Moda & 303,492 & 246,154 & 616,811 & 458,621 \\
\hline $\mathrm{F}$ & $39,908^{*}$ & $107,189^{*}$ & $25,571^{*}$ & $76,910^{*}$ \\
\hline $\mathrm{CV}(\%)$ & 2,825 & 1,423 & 1,597 & 1,286 \\
\hline
\end{tabular}

$\mathrm{x}=$ porcentagem de depósito do traçador em relação ao total aplicado; a, b e c são estimativas dos parâmetros do modelo para o traçador. ${ }^{*}$ significativo a $5 \%$ de probabilidade.
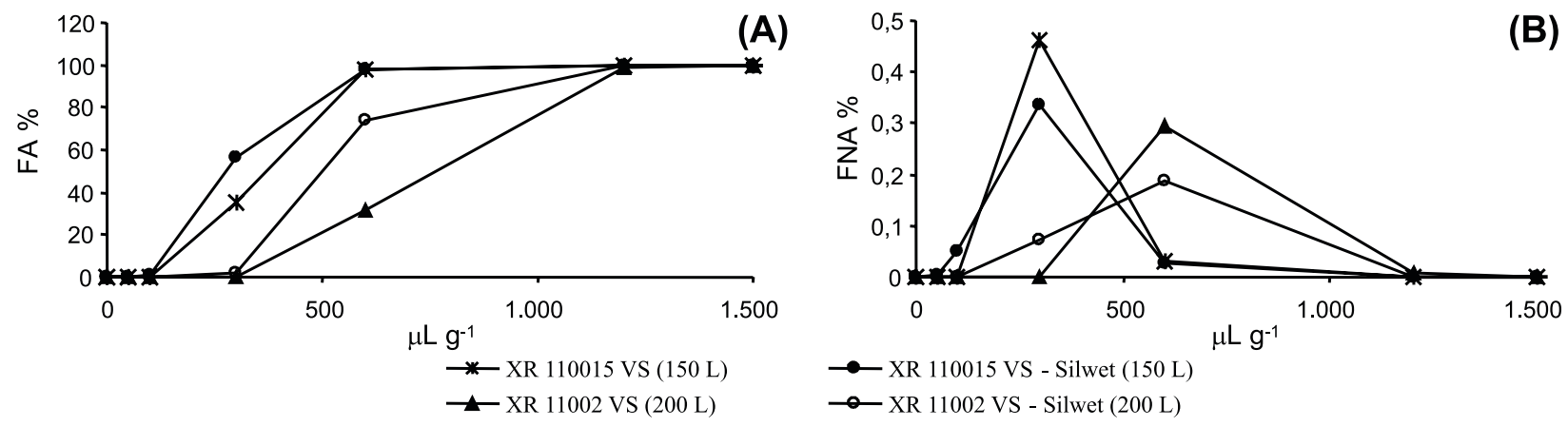

Figura 3 - Frequências acumuladas (FA\%): (A) e não acumuladas (FNA\%): (B), em função da deposição da calda de pulverização com e sem Silwet e dos volumes de aplicação, em $\mu \mathrm{L} \mathrm{g}^{-1}$ de massa seca das plantas de Bidens pilosa. 
Tabela 4 - Resultados das análises de regressão das frequências acumuladas dos depósitos da calda de pulverização com e sem a presença de Silwet na combinação de plantas de feijão e Brachiaria plantaginea, utilizando o modelo de Gompertz, bem como as médias, modas e medianas $\left(\mu \mathrm{L} \mathrm{g}^{-1}\right)$, dos diferentes volumes de aplicação

\begin{tabular}{|c|c|c|c|c|}
\hline \multirow{4}{*}{$\begin{array}{c}\text { Parâmetro } \\
\text { da } \\
\text { equação }\end{array}$} & \multicolumn{4}{|c|}{ Frequência acumulada (\%) $=\mathrm{e}^{\wedge}\left[\mathrm{a}-\mathrm{e}^{\wedge}\left(-\mathrm{b}-\mathrm{c}^{*} \mathrm{x}\right)\right]$} \\
\hline & \multirow{2}{*}{\multicolumn{2}{|c|}{$\begin{array}{c}\text { XR } 110015 \text { VS } \\
150\left(\mathrm{~L} \mathrm{ha}^{-1}\right)\end{array}$}} & \multirow{2}{*}{\multicolumn{2}{|c|}{$\begin{array}{c}\text { XR 11002 VS } \\
200\left(\mathrm{~L} \mathrm{ha}^{-1}\right)\end{array}$}} \\
\hline & & & & \\
\hline & $\begin{array}{c}\text { sem } \\
\text { surfatante }\end{array}$ & $\begin{array}{c}\text { com } \\
\text { surfatante }\end{array}$ & $\begin{array}{c}\text { sem } \\
\text { surfatante }\end{array}$ & $\begin{array}{c}\text { com } \\
\text { surfatante }\end{array}$ \\
\hline & \multicolumn{4}{|c|}{ Feijão } \\
\hline $\mathrm{a}$ & 4,605 & 4,605 & 4,605 & 4,605 \\
\hline $\mathrm{b}$ & $-3,913$ & $-4,177$ & $-2,141$ & $-4,155$ \\
\hline $\mathrm{c}$ & 0,024 & 0,016 & 0,009 & 0,014 \\
\hline Média & 175,187 & 297,653 & 236,597 & 344,374 \\
\hline Mediana & 178,313 & 293,130 & 269,046 & 325,289 \\
\hline Moda & 163,042 & 269,484 & 229,721 & 298,921 \\
\hline $\mathrm{F}$ & $76,303^{*}$ & $87,640^{*}$ & $55,968^{*}$ & $59,266^{*}$ \\
\hline \multirow[t]{2}{*}{$\mathrm{CV}(\%)$} & 4,650 & 2,470 & 3,840 & 2,512 \\
\hline & \multicolumn{4}{|c|}{ B. plantaginea } \\
\hline $\mathrm{a}$ & 4,605 & 4,605 & 4,605 & 4,605 \\
\hline $\mathrm{b}$ & $-0,529$ & $-0,618$ & $-1,715$ & $-0,166$ \\
\hline $\mathrm{c}$ & 0,003 & 0,005 & 0,004 & 0,011 \\
\hline Média & 471,906 & 265,555 & 695,324 & 82,048 \\
\hline Mediana & 294,577 & 208,142 & 571,844 & 47,125 \\
\hline Moda & 174,013 & 130,655 & 471,154 & 14,690 \\
\hline $\mathrm{F}$ & $78,473^{*}$ & $88,770^{*}$ & $279,983^{*}$ & $18,133^{*}$ \\
\hline $\mathrm{CV}(\%)$ & 1,735 & 2,934 & 0,632 & 18,935 \\
\hline
\end{tabular}

$\mathrm{x}=$ porcentagem de depósito do traçador em relação ao total aplicado; a, b e c são estimativas dos parâmetros do modelo para o traçador. ${ }^{*}$ significativo a $5 \%$ de probabilidade.
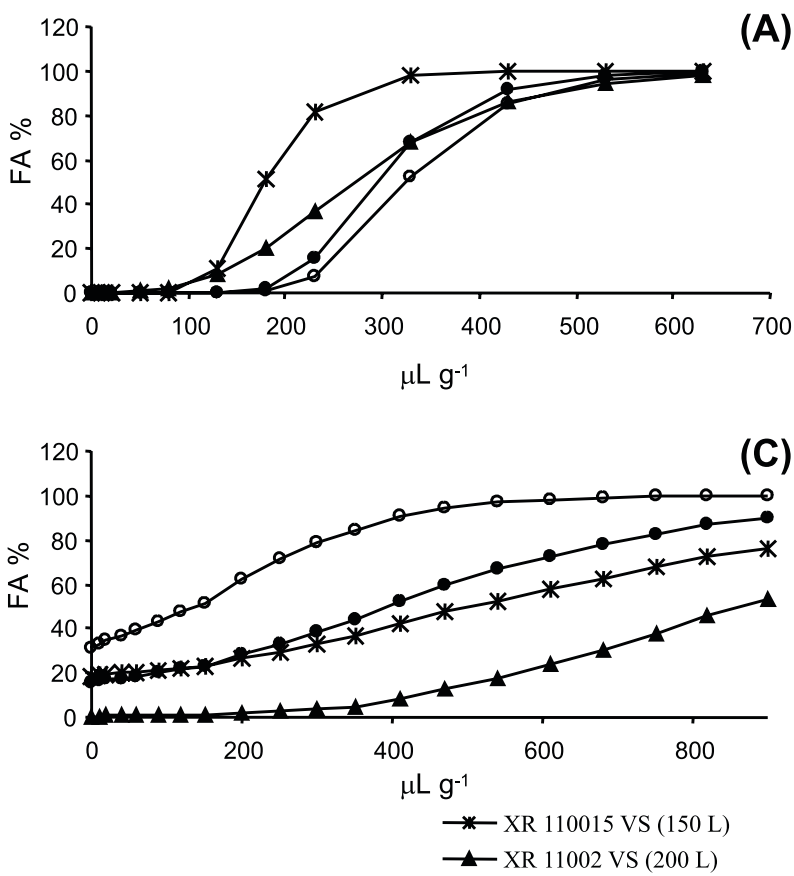

acentuados de depósitos nas plantas de B. plantaginea, sendo de 24,9 e 409,9\% para $150 \mathrm{~L} \mathrm{ha}^{-1}$; respectivamente; entretanto, a melhor uniformidade de distribuição das gotas foi obtida para as plantas de $B$. plantaginea também com o acréscimo do Silwet em ambos os volumes, porém com destaque para o volume de $200 \mathrm{~L} \mathrm{ha}^{-1}$.

Maciel et al. (2001) verificaram, em plantas de Brachiaria decumbens posicionadas sob as plantas de feijão, que as aplicações com a ponta TXVK-4 mais a adição do espalhante adesivo Aterbane $\operatorname{BR}\left(0,5 \% \mathrm{v} \mathrm{v}^{-1}\right)$ na calda de pulverização pode proporcionar deposição de gotas superior a 289,2 e 172,9\% em relação à ponta XR 11002 VS com e sem surfatante, respectivamente. Dessa forma, o efeito guarda-chuva promovido pelas plantas de feijão em aplicações de herbicidas para o controle de plantas daninhas pode ser minimizado com a redução da tensão superficial da água e utilização de pontas de pulverização que produzem gotas com diâmetro pequeno.

Por outro lado, esse procedimento pode aumentar a ocorrência de deriva, sendo necessário que as aplicações sejam realizadas quando as condições ambientais de temperatura,
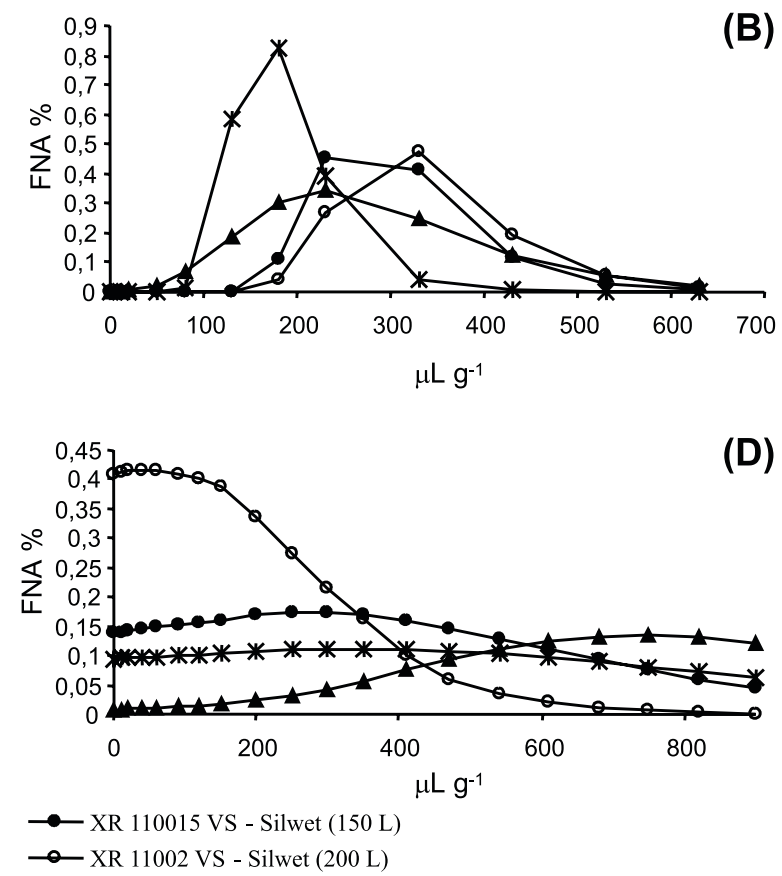

Figura 4 - Frequências acumuladas (FA\%) e não acumuladas (FNA\%) da combinação (feijão + Brachiaria plantaginea), em função da deposição da calda de pulverização com e sem Silwet e dos volumes de aplicação, em $\mu \mathrm{L} \mathrm{g}^{-1}$ de massa seca das plantas de feijão (A e B) e Brachiaria plantaginea (C e D). 
umidade relativa do ar e velocidade do vento estiverem favoráveis no momento das pulverizações (Lima \& Machado-Neto, 2001; Penckowski et al., 2003).

Souza et al. (2007) afirmam que pode ocorrer interferência do estádio de desenvolvimento sobre a deposição de gotas de pulverização, uma vez que a germinação das plantas daninhas é irregular e distribuída no tempo, encontrando-se, em um mesmo dia, plantas em vários estádios e de vários tamanhos. Além disso, as pequenas dimensões das plantas daninhas e a posição destas no campo, estando sujeitas ou não à cobertura pela cultura, também podem intensificar a variabilidade dos depósitos unitários. Esses autores revelam ainda que, ao se realizar a padronização das plantas daninhas dentro do mesmo intervalo de massa seca ou de área foliar, nos diferentes posicionamentos em campo (linha e entrelinha), observam-se maiores depósitos nas plantas presentes na entrelinha, em relação àquelas da linha da cultura.

Na combinação de plantas de feijão e B. pilosa (Tabela 5 e Figura 5), a presença do Silwet diminuiu a deposição da calda de pulverização em plantas de feijão, ao contrário
Tabela 5 - Resultados das análises de regressão das frequências acumuladas dos depósitos da calda de pulverização com e sem a presença de Silwet na combinação de plantas de feijão e Bidens pilosa, utilizando o modelo de Gompertz, bem como as médias, modas e medianas $\left(\mu \mathrm{L} \mathrm{g}^{-1}\right)$, dos diferentes volumes de aplicação

\begin{tabular}{|c|c|c|c|c|}
\hline \multirow{4}{*}{$\begin{array}{c}\text { Parâmetro } \\
\text { da } \\
\text { equação }\end{array}$} & \multicolumn{4}{|c|}{ Frequência acumulada $(\%)=\mathrm{e}^{\wedge}\left[\mathrm{a}-\mathrm{e}^{\wedge}\left(-\mathrm{b}-\mathrm{c}^{*} \mathrm{x}\right)\right]$} \\
\hline & \multirow{2}{*}{\multicolumn{2}{|c|}{$\begin{array}{c}\text { XR } 110015 \mathrm{VS} \\
150\left(\mathrm{~L} \mathrm{ha}^{-1}\right) \\
\end{array}$}} & \multirow{2}{*}{\multicolumn{2}{|c|}{$\begin{array}{c}\text { XR 11002 VS } \\
200\left(\mathrm{~L} \mathrm{ha}^{-1}\right)\end{array}$}} \\
\hline & & & & \\
\hline & $\begin{array}{c}\text { sem } \\
\text { surfatante }\end{array}$ & $\begin{array}{c}\text { com } \\
\text { surfatante }\end{array}$ & $\begin{array}{c}\text { sem } \\
\text { surfatante }\end{array}$ & $\begin{array}{c}\text { com } \\
\text { surfatante }\end{array}$ \\
\hline & \multicolumn{4}{|c|}{ Feijão } \\
\hline $\mathrm{a}$ & 4,605 & 4,605 & 4,605 & 4,605 \\
\hline $\mathrm{b}$ & $-3,734$ & $-2,424$ & $-3,137$ & $-4,220$ \\
\hline $\mathrm{c}$ & 0,019 & 0,016 & 0,011 & 0,021 \\
\hline Média & 236,608 & 161,956 & 315,153 & 237,111 \\
\hline Mediana & 219,279 & 180,033 & 315,632 & 222,646 \\
\hline Moda & 199,679 & 156,387 & 282,613 & 204,854 \\
\hline $\mathrm{F}$ & $46,720^{*}$ & $163,993^{*}$ & $73,916^{*}$ & $228,270^{*}$ \\
\hline \multirow[t]{2}{*}{$\mathrm{CV}(\%)$} & 4,102 & 3,305 & 2,492 & 1,903 \\
\hline & \multicolumn{4}{|c|}{ B. pilosa } \\
\hline $\mathrm{a}$ & 4,605 & 4,605 & 4,605 & 4,605 \\
\hline $\mathrm{b}$ & $-1,846$ & $-0,384$ & $-2,286$ & $-0,014$ \\
\hline $\mathrm{c}$ & 0,004 & 0,015 & 0,003 & 0,002 \\
\hline Média & 652,017 & 122,350 & 892,349 & 326,728 \\
\hline Mediana & 614,587 & 50,034 & $1.012,410$ & 187,248 \\
\hline Moda & 512,778 & 25,600 & 872,519 & 6,700 \\
\hline $\mathrm{F}$ & $19,282 *$ & $9,399^{*}$ & $25,610^{*}$ & $1,720^{*}$ \\
\hline $\mathrm{CV}(\%)$ & 1,839 & 13,539 & 1,152 & 9,512 \\
\hline
\end{tabular}

$\mathrm{x}=$ porcentagem de depósito do traçador em relação ao total aplicado; a, b e c são estimativas dos parâmetros do modelo para o traçador. ${ }^{*}$ significativo a $5 \%$ de probabilidade.
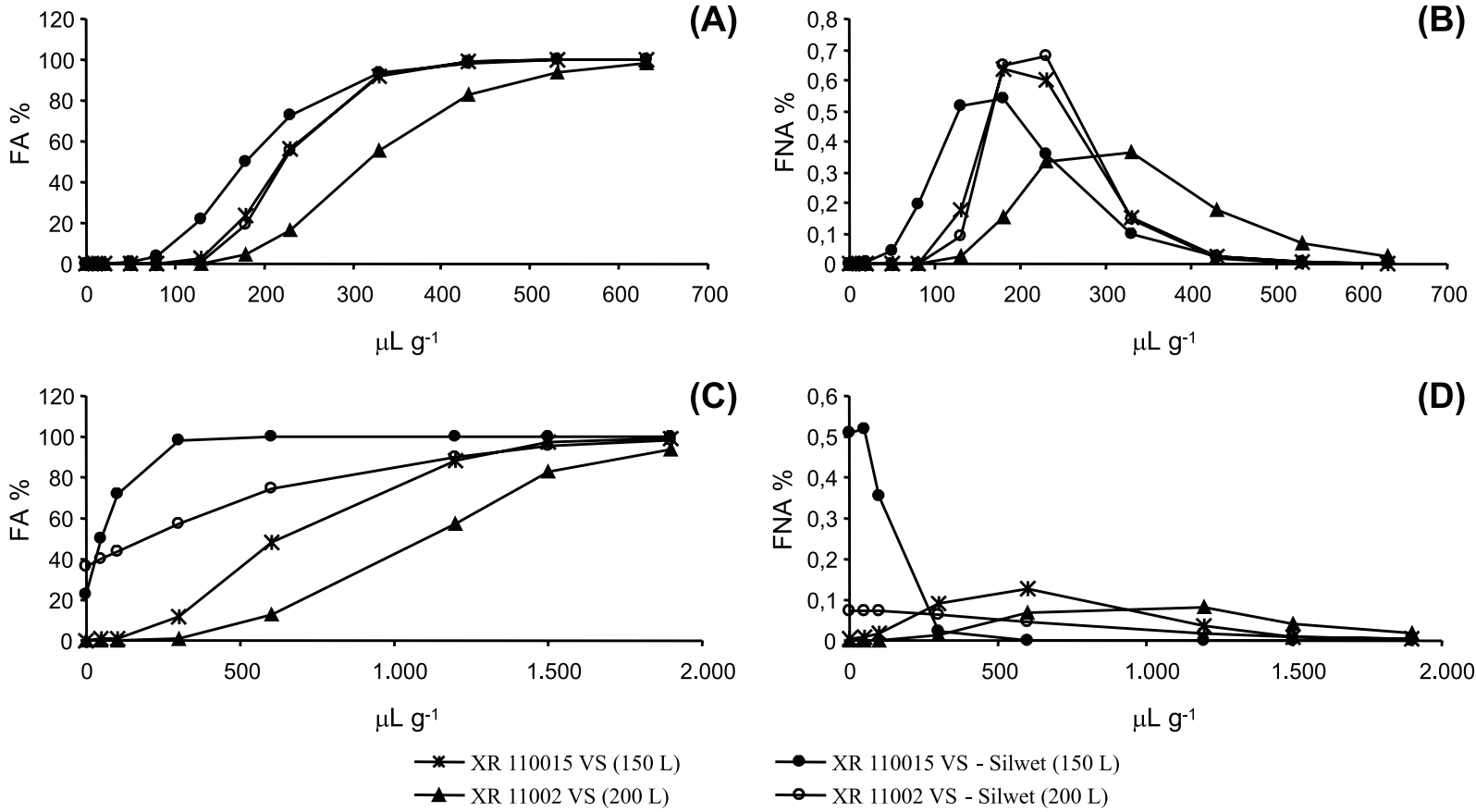

Figura 5 - Frequências acumuladas (FA\%) e não acumuladas (FNA\%) da combinação (feijão + Bidens pilosa), em função da deposição da calda de pulverização com e sem Silwet e dos volumes de aplicação, em $\mu \mathrm{L} \mathrm{g}^{-1}$ de massa seca das plantas de feijão (A e B) e Bidens pilosa (C e D). 
do que ocorreu com a combinação com $B$. plantaginea; esse fato deve-se provave1mente à maior semelhança entre a morfologia de feijão e $B$. pilosa, os quais possuem maior área foliar em comparação a $B$. plantaginea. Nesse caso, de forma semelhante ao acontecido com B. plantaginea, também o uso de Silwet na solução aplicada determinou decréscimos de depósitos nas plantas de B. pilosa. Esses resultados corroboram os obtidos quando se pulverizaram as caldas na espécie $B$. pilosa sem a presença das plantas de feijão. Contudo, pode-se constatar também que as plantas de feijão influenciaram significativamente na deposição das gotas nas plantas de B. pilosa, principalmente com a utilização do surfatante organossiliconado Silwet.

Na pulverização realizada na combinação das duas plantas daninhas (Tabela 6 e Figura 6) verificou-se que, enquanto houve incremento na deposição de gotas para as plantas de $B$. plantaginea no volume de $150 \mathrm{~L} \mathrm{ha}^{-1}$ com a adição do Silwet, houve decréscimo da deposição quando se aplicaram $200 \mathrm{~L} \mathrm{ha}^{-1}$ com a adição do Silwet. Comportamento inverso foi observado para B. pilosa, que apresentou maior deposição de gotas no
Tabela 6 - Resultados das análises de regressão das frequências acumuladas dos depósitos da calda de pulverização com e sem a presença de Silwet em combinações de plantas de Brachiaria plantaginea e Bidens pilosa, utilizando o modelo de Gompertz, bem como as médias, modas e medianas $\left(\mu \mathrm{Lg}^{-1}\right)$, dos diferentes volumes de aplicação

\begin{tabular}{|c|c|c|c|c|}
\hline \multirow{4}{*}{$\begin{array}{c}\text { Parâmetro } \\
\text { da } \\
\text { equação }\end{array}$} & \multicolumn{4}{|c|}{ Frequência acumulada $(\%)=\mathrm{e}^{\wedge}\left[\mathrm{a}-\mathrm{e}^{\wedge}\left(-\mathrm{b}-\mathrm{c}^{*} \mathrm{x}\right)\right]$} \\
\hline & \multirow{2}{*}{\multicolumn{2}{|c|}{$\begin{array}{l}\text { XR } 110015 \text { VS } \\
150\left(\mathrm{~L} \mathrm{ha}^{-1}\right)\end{array}$}} & \multirow{2}{*}{\multicolumn{2}{|c|}{$\begin{array}{c}\text { XR } 11002 \text { VS } \\
200\left(\mathrm{~L} \mathrm{ha}^{-1}\right)\end{array}$}} \\
\hline & & & & \\
\hline & $\begin{array}{c}\text { sem } \\
\text { surfatante }\end{array}$ & $\begin{array}{c}\text { com } \\
\text { surfatante }\end{array}$ & $\begin{array}{c}\text { sem } \\
\text { surfatante }\end{array}$ & $\begin{array}{c}\text { com } \\
\text { surfatante }\end{array}$ \\
\hline & \multicolumn{4}{|c|}{ B. plantaginea } \\
\hline $\mathrm{a}$ & 4,605 & 4,605 & 4,605 & 4,605 \\
\hline $\mathrm{b}$ & $-0,988$ & $-2,506$ & $-2,388$ & $-3,368$ \\
\hline $\mathrm{c}$ & 0,011 & 0,011 & 0,007 & 0,014 \\
\hline Média & 117,633 & 308,986 & 339,431 & 271,888 \\
\hline Mediana & 125,418 & 254,205 & 378,888 & 270,617 \\
\hline Moda & 91,481 & 221,770 & 328,473 & 244,058 \\
\hline $\mathrm{F}$ & $136,127 *$ & $252,446^{*}$ & $246,794 *$ & $204,808^{*}$ \\
\hline \multirow[t]{2}{*}{$\mathrm{CV}(\%)$} & 5,586 & 1,508 & 1,422 & 2,019 \\
\hline & \multicolumn{4}{|c|}{ B. pilosa } \\
\hline $\mathrm{a}$ & 4,605 & 4,605 & 4,605 & 4,605 \\
\hline $\mathrm{b}$ & $-4,598$ & $-1,977$ & $-3,288$ & $-1,739$ \\
\hline $\mathrm{c}$ & 0,009 & 0,008 & 0,006 & 0,002 \\
\hline Média & 654,419 & 241,071 & 901,746 & 395,945 \\
\hline Mediana & 564,149 & 295,525 & 617,316 & $1.063,390$ \\
\hline Moda & 522,500 & 249,306 & 555,405 & 878,283 \\
\hline $\mathrm{F}$ & $21,549^{*}$ & $29,039^{*}$ & $22,891^{*}$ & $33,465^{*}$ \\
\hline $\mathrm{CV}(\%)$ & 1,697 & 4,037 & 1,197 & 2,390 \\
\hline
\end{tabular}

$\mathrm{x}=$ porcentagem de depósito do traçador em relação ao total aplicado; a, b e c são estimativas dos parâmetros do modelo para o traçador. ${ }^{*}$ significativo a $5 \%$ de probabilidade.
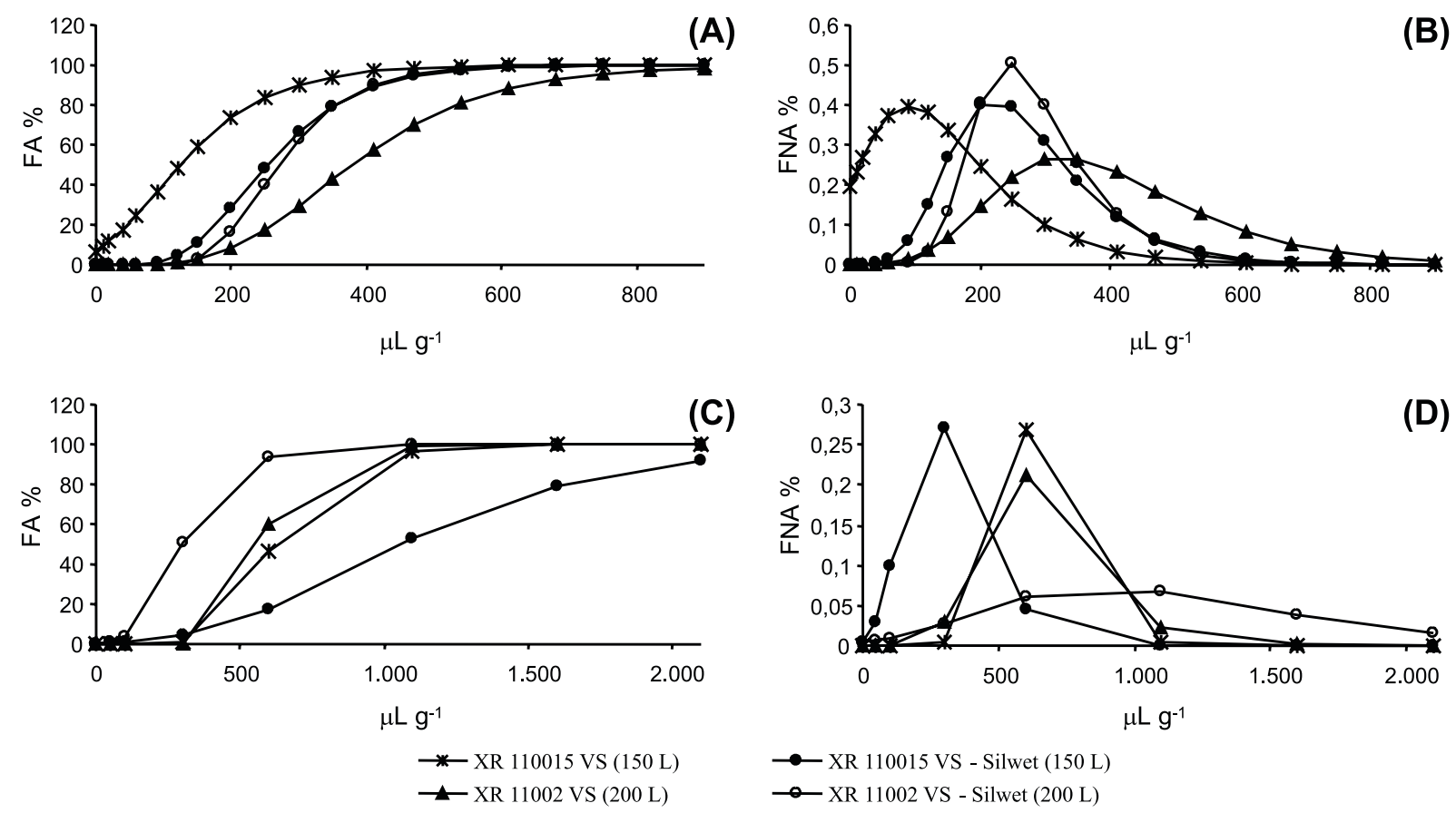

Figura 6 - Frequências acumuladas (FA\%): (A e C) e não acumuladas (FNA\%): (B e D) da combinação (Brachiaria plantaginea + Bidens pilosa), em função da deposição da calda de pulverização com e sem Silwet e dos volumes de aplicação, em $\mu \mathrm{L} \mathrm{g}{ }^{-1}$ de massa seca das plantas de Brachiaria plantaginea (A e B) e Bidens pilosa (C e D). 
volume de $200 \mathrm{~L} \mathrm{ha}^{-1}$ e menor no de $150 \mathrm{~L} \mathrm{ha}^{-1}$, com a adição do surfatante.

Portanto, ficou evidenciado que, nas condições deste trabalho, a obtenção de maiores depósitos, na superficie das folhas, é dependente do volume de aplicação, da adição de surfatante e da espécie de planta avaliada.

Para a pulverização realizada na combinação das plantas de feijão e das duas plantas daninhas (Tabela 7 e Figura 7), verificou-se que houve incremento na deposição de gotas apenas para as plantas de B. pilosa com a presença de surfatante no volume de $200 \mathrm{~L} \mathrm{ha}^{-1}$; a melhor uniformidade de distribuição das gotas foi obtida quando se utilizou o menor volume com o surfatante em todas as espécies. Esse fato evidencia que a utilização do Silwet na calda de pulverização pode modificar o espectro de gotas produzidas pelas pontas XR e que a uniformidade de distribuição delas é maior em volumes reduzidos. Da mesma maneira, com a ausência do surfatante na calda de pulverização pode haver irregularidades nos depósitos, levando à necessidade de aumento na dose do herbicida, sobretudo os de ação de contato, em determinada condição de infestação de plantas daninhas.

Souza et al. (2007) concluíram que a presença das plantas daninhas próximo da linha da cultura pode promover irregularidades nos depósitos das gotas de pulverização e exigir aumento na dose de herbicidas para que elevados níveis de eficiência de controle sejam alcançados em condições de campo.

Com base nos resultados do presente trabalho, pode-se observar que as gotas da calda de pulverização proporcionadas pelas pontas XR podem ser retidas em quantidades distintas pelas espécies avaliadas e que, dependendo do tipo de infestação de plantas daninhas na cultura do feijão, pode haver falhas na deposição no alvo.

Contudo, devido à ampla variabilidade dos valores dos depósitos correspondentes aos arranjos avaliados entre o feijoeiro e as plantas daninhas $B$. plantaginea e B. pilosa, pode-se constatar que o manejo dessas espécies em pós-emergência implicaria o emprego de diferentes volumes de aplicação com a adição ou não de surfatante, de acordo com o tipo de
Tabela 7 - Resultados das análises de regressão das frequências acumuladas dos depósitos da calda de pulverização com e sem a presença de Silwet em combinação de plantas de feijão, Brachiaria plantaginea e Bidens pilosa, utilizando o modelo de Gompertz, bem como as médias, modas e medianas $\left(\mu \mathrm{L} \mathrm{g}^{-1}\right)$, dos diferentes volumes de aplicação

\begin{tabular}{|c|c|c|c|c|}
\hline \multirow{4}{*}{$\begin{array}{l}\text { Parâmetro } \\
\text { da } \\
\text { equação }\end{array}$} & \multicolumn{4}{|c|}{ Frequência acumulada $(\%)=\mathrm{e}^{\wedge}\left[\mathrm{a}-\mathrm{e}^{\wedge}\left(-\mathrm{b}-\mathrm{c}^{*} \mathrm{x}\right)\right]$} \\
\hline & \multirow{2}{*}{\multicolumn{2}{|c|}{$\frac{\text { XR } 110015 \text { VS }}{150\left(\mathrm{~L} \mathrm{ha}^{-1}\right)}$}} & \multirow{2}{*}{\multicolumn{2}{|c|}{$\frac{\text { XR } 11002 \text { VS }}{200\left(\mathrm{~L} \mathrm{ha}^{-1}\right)}$}} \\
\hline & & & & \\
\hline & $\begin{array}{c}\text { sem } \\
\text { surfatante }\end{array}$ & $\begin{array}{c}\text { com } \\
\text { surfatante }\end{array}$ & $\begin{array}{c}\text { sem } \\
\text { surfatante }\end{array}$ & $\begin{array}{c}\text { com } \\
\text { surfatante }\end{array}$ \\
\hline & \multicolumn{4}{|c|}{ Feijão } \\
\hline $\mathrm{a}$ & 4,605 & 4,605 & 4,605 & 4,605 \\
\hline $\mathrm{b}$ & $-4,196$ & $-6,561$ & $-7,383$ & $-3,347$ \\
\hline $\mathrm{c}$ & 0,019 & 0,035 & 0,028 & 0,016 \\
\hline Média & 256,805 & 212,822 & 292,245 & 234,572 \\
\hline Mediana & 240,132 & 200,797 & 272,870 & 229,229 \\
\hline Moda & 220,842 & 190,174 & 259,965 & 206,605 \\
\hline F & $123,282 *$ & $117,244^{*}$ & $92,264^{*}$ & $122,153^{*}$ \\
\hline \multirow[t]{2}{*}{$\mathrm{CV}(\%)$} & 2,408 & 3,008 & 2,544 & 2,605 \\
\hline & \multicolumn{4}{|c|}{ B. plantaginea } \\
\hline $\mathrm{a}$ & 4,605 & 4,605 & 4,605 & 4,605 \\
\hline $\mathrm{b}$ & $-1,188$ & $-0,480$ & $-0,971$ & $-0,323$ \\
\hline $\mathrm{c}$ & 0,004 & 0,006 & 0,002 & 0,004 \\
\hline Média & 493,715 & 131,998 & 699,077 & 172,865 \\
\hline Mediana & 352,497 & 138,545 & 786,772 & 155,646 \\
\hline Moda & 269,388 & 78,560 & 571,176 & 72,912 \\
\hline $\mathrm{F}$ & $582,608^{*}$ & $47,739^{*}$ & $339,480 *$ & $27,020^{*}$ \\
\hline \multirow[t]{2}{*}{ CV (\%) } & 0,627 & 7,838 & 0,573 & 7,662 \\
\hline & \multicolumn{4}{|c|}{ B. pilosa } \\
\hline $\mathrm{a}$ & 4,605 & 4,605 & 4,605 & 4,605 \\
\hline b & $-2,351$ & $-0,384$ & $-1,627$ & $-0,916$ \\
\hline $\mathrm{c}$ & 0,004 & 0,008 & 0,002 & 0,001 \\
\hline Média & 964,985 & 165,727 & 775,783 & 378,043 \\
\hline Mediana & 769,834 & 99,274 & $1.011,935$ & 2471,123 \\
\hline Moda & 666,006 & 50,794 & 825,888 & $1.764,933$ \\
\hline $\mathrm{F}$ & $55,461^{*}$ & $9,119^{*}$ & $59,481^{*}$ & $13,569^{*}$ \\
\hline CV (\%) & 0,736 & 10,114 & 0,906 & 3,688 \\
\hline
\end{tabular}

$\mathrm{x}=$ porcentagem de depósito do traçador em relação ao total aplicado; a, b e c são estimativas dos parâmetros do modelo para o traçador. ${ }^{*}$ significativo a $5 \%$ de probabilidade.

espécie presente na área. Assim, a recomendação generalizada de determinada ponta de pulverização ou de volume de aplicação com ou sem surfatante apresenta-se extremamente difícil, sendo necessária a realização de mais estudos sobre o assunto. 

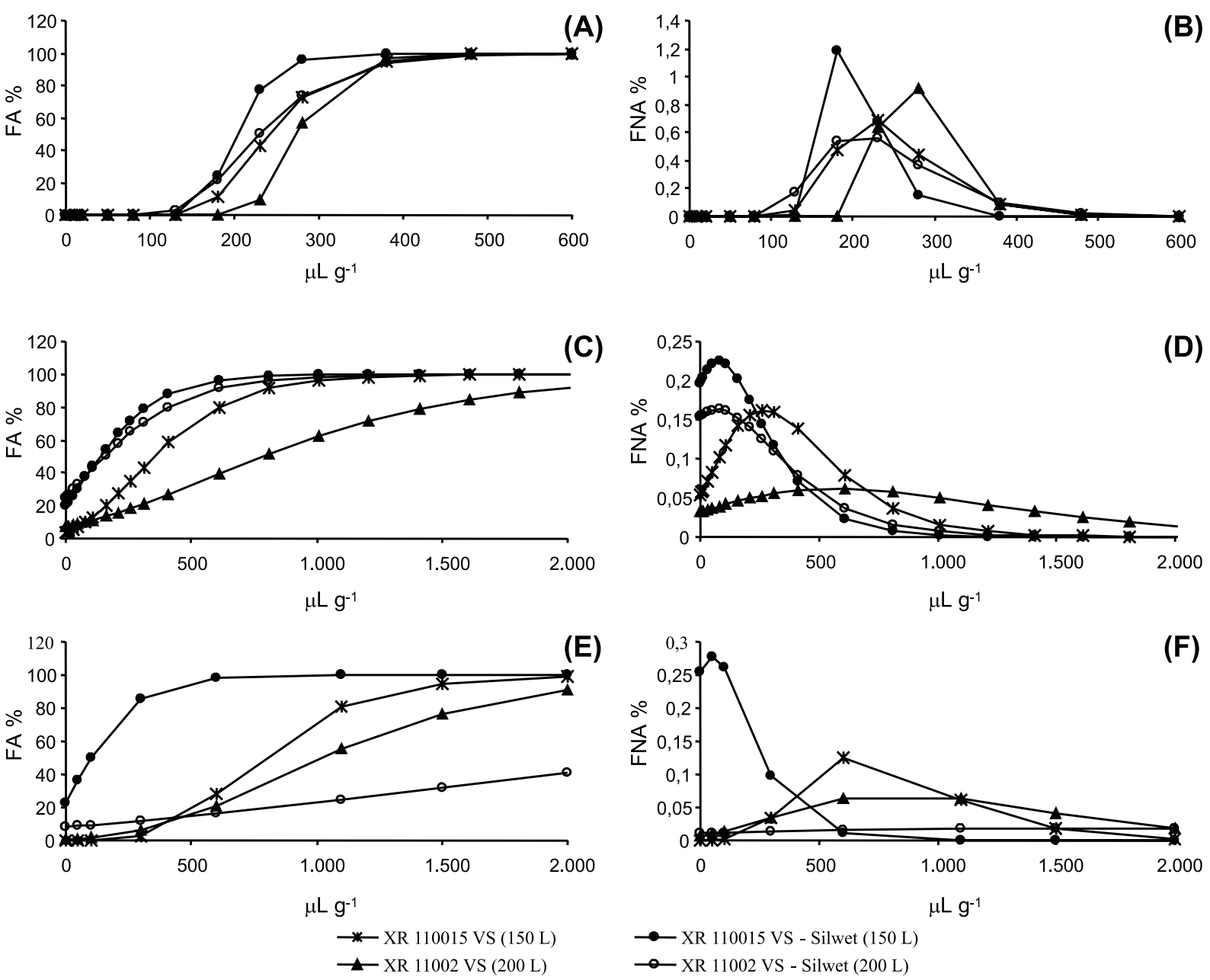

Figura 7 - Frequências acumuladas (FA\%): (A; C e E) e não acumuladas (FNA\%): (B; D e F) da combinação (feijão + Brachiaria plantaginea + Bidens pilosa), em função da deposição da calda de pulverização com e sem Silwet e dos volumes de aplicação, em $\mu \mathrm{L} \mathrm{g}^{-1}$ de massa seca das plantas de feijão (A e B), Brachiaria plantaginea (C e D) e Bidens pilosa (E e F).

\section{LITERATURA CITADA}

BUICK, R. D.; BUCHAN, G. D.; FIELD, R. J. The role of surface tension of spreading droplets in absorption of a herbicide formulation via leaf stomata. Pest. Sci., v. 38, n. 2/3, p. 227-235, 1993.

COSTA, N. V. et al. Ph foliar e deposição de gotas de pulverização em plantas daninhas aquáticas: Brachiaria mutica, Brachiaria subquadripara e Panicum repens.

Planta Daninha, v. 23, n. 2, p. 295-304, 2005.

CUNHA, J. P. A. R. et al. Avaliação de estratégias para redução da deriva de agrotóxicos em pulverizações hidráulicas. Planta Daninha, v. 21, n. 2, p. 325-332, 2003.

CUNHA, J. P. A. R. et al. Deposição e deriva de calda fungicida aplicada em feijoeiro, em função de bico de pulverização e de volume de calda. R. Bras. Eng. Agríc. Amb., v. 9, n. 1, p. 133-38, 2005.
DOWNER, R. A. et al. Herbicide spray distribution, quality and efficacy interactions: conflicts in requirements. Aspects App. Biol., v. 1, n. 48, p. 79-89, 1997.

FERNANDES, A. P. et al. Caracterização do perfil de deposição e do diâmetro de gotas e otimização do espaçamento entre bicos na barra de pulverização. Eng. Agríc., v. 27, n. 3, p. 728-733, 2007.

FERREIRA, E. A. et al. Leaf blade quantitative anatomy of sugarcane cultivars and clones. Planta Daninha, v. 25, n. 1, p. $25-34,2007$

GUIMARÃES, A. A. et al. Composição química da cera epicuticular de biótipos de azevém resistente e suscetível ao glyphosate. Planta Daninha, v. 27, n. 1, p. 149-154, 2009.

HESS, F. D.; FALK, R. H. Herbicide deposition on leaf surfaces. Weed Sci., v. 38, n. 3, p. 280-288, 1990 
LIMA, P. R. F.; MACHADO-NETO, J. G. Otimização da aplicação de fluazifop-p-butil em pós-emergência na cultura de soja (Glycine max). Planta Daninha, v. 19, n. 1, p. 85-95, 2001.

MACIEL, C. D. G. et al. Avaliação do depósito e distribuição da calda de pulverização em plantas de feijoeiro e Braquiaria decumbens. Planta Daninha, v. 19, n. 1, p. 103-110, 2001.

MENDONÇA, C. G. et al. Efeitos de surfatantes sobre a tensão superficial e área de molhamento de soluções de glyphosate sobre folhas de tiririca. Planta Daninha, v. 17, n. 3, p. 355-366, 1999.

MENDONÇA, C. G. Algumas características da superfície foliar de diversas plantas daninhas monocotiledôneas. 2000. 89 f. Dissertação (Mestrado em Agronomia) - Universidade Estadual Paulista "Júlio de Mesquita Filho", Botucatu, 2000.

MONQUERO, P. A.; CURY, J. C.; CHRISTOFFOLETI, P. J Controle pelo glyphosate e caracterização geral da superfície foliar de Commelina benghalensis, Ipomoea hederifolia, Richardia brasiliensis e Galinsoga parviflora.

Planta Daninha, v. 23, n. 1, p. 123-132, 2005.

PENCKOWSKI, L. H.; PODOLAN, M. J.; LÓPEZOVEJERO, R. F. Influência das condições climáticas no momento da aplicação de herbicidas pós-emergentes sobre a eficácia de controle de nabiça (Raphanus raphanistrum) na cultura de trigo. Planta Daninha, v. 21, n. 3, p. 435-442, 2003.

PROCÓPIO, S. O. et al. Estudos anatômicos de folhas de espécies de plantas daninhas de grande ocorrência no Brasil. v - Leonurus sibiricus, Leonotis nepetaefolia, Plantago tomentosa e Sida glaziovii. Planta Daninha, v. 21, n. 3, p. 403-411, 2003.
QUINTELA, E. D. Manejo integrado de pragas do feijoeiro. Santo Antônio de Goiás: Embrapa Arroz e Feijão, 2001. 28 p. (Circular Técnica, 46)

RAETANO, C. G.; BAUER, F. Deposição e perdas da calda em feijoeiro em aplicação com assistência de ar na barra pulverizadora. Bragantia, v. 63, n. 2, p. 309-315, 2004.

RODRIGUES, B. N.; ALMEIDA, F. S. Guia de herbicidas. 5.ed. Londrina: 2005. 592 p.

SHARP, D. B. A rapid method of spray deposit measurement and its use in new apple orchards. In: BRITISH INSECTICIDE AND FUNGICIDE CONFERENCE, 7. 1973, Brighton. Proceedings... Brighton: British Crop Protection Council, 1973. p. 637-642

SOUZA, R. T;; VELINI, E. D;; PALLADINI, L. A. Aspectos metodológicos para análise de depósitos de pulverizações pela determinação dos depósitos pontuais. Planta Daninha, v. 25, n. 1, p. $195-202,2007$.

SPRAYING SYSTEMS CO. Teejet tecnologies a sparring systems company - Catálogo 50-P. 2007. 196 p.

STOCK, D.; HOLLOWAY, P. J. Possible mechanisms for surfactant-induced foliar uptake of agrochemicals. Pest. Sci., v. 38, n. $2 / 3$, p. $165-177,1993$.

TOMAZELA, M. S. et al. Avaliação da deposição da calda de pulverização em função da densidade populacional de Brachiaria plantaginea, do volume e do ângulo de aplicação. Planta Daninha, v. 24, n. 1, p. 183-189, 2006.

VELINI, E. D. Estudos e desenvolvimento de métodos experimentais e amostrais adaptados à matologia. 1995 250 f. Tese (Doutorado em Agronomia/Produção Vegetal) Faculdade de Ciências Agrárias e Veterinárias, Universidade Estadual Paulista, Jaboticabal, 1995. 